\title{
Low-intensity pulsed ultrasound inhibits lipopolysaccharide- induced IL-6 and RANKL expression in osteoblasts
}

\author{
Mayu Nagao ${ }^{1)}$, Natsuko Tanabe2,3), Soichiro Manaka4), Tadahiro Takayama ${ }^{4,5)}$, \\ Takayuki Kawato ${ }^{3,6)}$, Go Torigoe1), Jumpei Sekino'1), Naoya Tsukune1), \\ Manami Ozaki1), Masao Maeno ${ }^{3,6)}$, Naoto Suzuki2,3), and Shuichi Sato 4,5$)$ \\ 1)Division of Applied Oral Science, Nihon University Graduate School of Dentistry, Tokyo, Japan \\ 2)Department of Biochemistry, Nihon University School of Dentistry, Tokyo, Japan \\ 3)Division of Functional Morphology, Dental Research Center, Nihon University School of Dentistry, \\ Tokyo, Japan \\ 4)Department of Periodontology, Nihon University School of Dentistry, Tokyo, Japan \\ 5)Division of Advanced Dental Treatment, Dental Research Center, Nihon University School of Dentistry, \\ Tokyo, Japan \\ ${ }^{6}$ Department of Oral Health Sciences, Nihon University School of Dentistry, Tokyo, Japan
}

(Received August 23, 2016; Accepted October 25, 2016)

\begin{abstract}
Periodontal disease is caused by inflammation induced by Porphyromonas gingivalis (P.g.) lipopolysaccharide (LPS) and involves expression of proinflammatory cytokines such as interleukin (IL)-1, IL-6, tumor necrosis factor- $\alpha$, and receptor activator of nuclear factor kappa B ligand (RANKL), which are implicated in bone resorption. Low-intensity pulsed ultrasound (LIPUS) is commonly used in the treatment of bone fracture. However, the mechanisms by which LIPUS inhibits LPS-induced inflammatory cytokines are poorly understood. Therefore, we investigated the effects of LIPUS on LPS-induced expression of the proinflammatory cytokines IL-6 and RANKL. MC3T3-E1 cells were incubated in the presence or absence of P.g. LPS and then stimulated with LIPUS for $30 \mathrm{~min} /$ day for a maximum of 14 days. LPS increased mRNA and protein expressions of IL-6 and RANKL on day 14. In addition, mRNA expression of COX-2 LPS was higher after 3 and 7
\end{abstract}

Correspondence to Dr. Natsuko Tanabe, Department of Biochemistry, Nihon University School of Dentistry, 1-8-13 Kanda-Surugadai, Chiyoda-ku, Tokyo 101-8310, Japan Fax:+81-3-3219-8334 E-mail: tanabe.natsuko@nihon-u.ac.jp

doi.org/10.2334/josnusd.16-0624

DN/JST.JSTAGE/josnusd/16-0624 days of LIPUS treatment. PGE $_{2}$ was induced by LPS after 7 and 14 days of culture. LIPUS suppressed all stimulatory effects of LPS. These results suggest that LIPUS inhibits LPS-induced expression of inflammation cytokines by suppressing $\mathrm{PGE}_{2}$ production and might thus have potential applications in the treatment of periodontitis.

Keywords: LIPUS; LPS; proinflammatory cytokine; $\mathrm{PGE}_{2}$.

\section{Introduction}

Chronic inflammatory bone diseases such as rheumatoid arthritis (RA) and periodontal disease are common. RA affects more than 23 million people worldwide, and $47 \%$ of adults 30 years or older have periodontal disease (1).

Periodontal disease is caused by alveolar bone resorption induced by lipopolysaccharide (LPS) from Porphyromonas gingivalis (P.g.). LPS is a constituent of membranes of gram-negative bacteria and stimulates Tolllike receptor (TLR) 4 and 2, which increase inflammatory cytokines/chemokines and regulate subsequent adaptive immune responses (2). Inflammatory bone disease is associated with the inflammatory cytokines interleukin (IL)-1, IL-6, and tumor necrosis factor (TNF)- $\alpha$ (3). 
LPS, receptor activator of nuclear factor kappa B ligand (RANKL), IL-1, and TNF- $\alpha$ are responses to the differentiation and activation of osteoclasts, which promote bone resorption (4). Furthermore, P.g.-associated LPS increases RANKL, IL-1, and IL-6 in osteoblasts (5-7). Thus, LPS and LPS-induced proinflammatory cytokines are important factors in periodontal disease progression.

Low-intensity pulsed ultrasound (LIPUS) is a form of mechanical stimulation that facilitates healing and regeneration of bone fractures and induces osseointegration of dental implants. LIPUS is therefore used in several clinical settings (8-12). In a previous clinical study, continuous LIPUS stimulation shortened the healing index of bone fracture by 12 days $/ \mathrm{cm}$; thus, callus maturation was $27 \%$ faster during LIPUS. LIPUS reduced fixator time for 95 days as compared with the absence of LIPUS stimulation (13). In previous studies, the usual conditions for LIPUS were $30 \mathrm{~mW} / \mathrm{cm}^{2} \mathrm{SATA}$; intensity, $1.5 \mathrm{MHz}, 1 \mathrm{kHz}$; pulsed with an exposure time of 20 min for osteoblasts (14). LIPUS exhibits various effects, including acoustic streaming, acoustic radiation force, and propagation of surface waves. Promotion of fluid flow increases circulation and promotes redistribution of nutrients, oxygen, and signaling molecules. In contrast, high-intensity ultrasound damaged DNA and caused degradation (15). In addition, LIPUS does not induce a cavitation effect on pressure levels or transform acoustic wave energy into heat. LIPUS induced osteoblast differentiation and osteogenesis in vitro in previous studies $(14,16)$. LIPUS also inhibited inflammatory chemokines induced by LPS in osteoblasts (17). However, the effects of continuous LIPUS stimulation on LPS-induced inflammatory cytokine expression are poorly understood. In the present study, we investigated the effect of continuous LIPUS on the production of bone resorption-related proinflammatory cytokines in the MC3T3-E1 osteoblastic cell line.

\section{Materials and Methods}

Cell culture

The mouse calvarial cell line MC3T3-E1 was obtained from Riken BioResource Center (Tsukuba, Japan) for osteoblasts. Cells were maintained in $\alpha$-minimal essential medium (MEM; Wako, Tokyo, Japan) containing 10 $\%(\mathrm{v} / \mathrm{v})$ heat-inactivated fetal bovine serum (HyClone Laboratories, Logan, UT, USA) and $1 \%(\mathrm{v} / \mathrm{v})$ penicillinstreptomycin solution (Wako, Tokyo, Japan) at $37^{\circ} \mathrm{C}$ in a humidified atmosphere of $95 \%$ air and $5 \% \mathrm{CO}_{2}$. Cells were treated with $10 \mu \mathrm{g} / \mathrm{mL}$ LPS (P.g.) (InvivoGen, San Diego, CA, USA) or left untreated. The medium was replaced every 3 days.

\section{LIPUS stimulation}

Cells were plated in 6-well culture plates (Iwaki, Tokyo, Japan) at a density of $2 \times 10^{4}$ cells $/ \mathrm{cm}^{2}$ for $24 \mathrm{~h}$ before LIPUS stimulation (1.5 MHz; pulsed-wave mode intensity, $30 \mathrm{~mW} / \mathrm{cm}^{2}$ ) with a sterilized transducer (Osteotron $\mathrm{D}^{2}$; Ito Co., Tokyo, Japan) placed on the surface of the culture medium. The distance between the transducer and cells was approximately 3-4 $\mathrm{mm}$. Untreated control cells were not stimulated with LIPUS.

\section{Real-time PCR}

Cells were plated on 6-well plates and cultured for up to 14 days. Briefly, total RNA was isolated on days 3, 7, and 14 of culture. We described the methods in detail in our previous report (18). mRNA expression was detected by real-time PCR. The primer sequences of IL-6, RANKL, and COX-2 are shown in Table 1 . The cycling conditions were 35 cycles at $95^{\circ} \mathrm{C}$ for $5 \mathrm{~s}$ and $60^{\circ} \mathrm{C}$ for 20 $\mathrm{s}$. The calculated values for target gene expression were normalized to the level of glyceraldehyde-3-phosphate dehydrogenase (GAPDH), which was used as the internal control.

\section{Enzyme-linked immunosorbent assay (ELISA)}

Cells were cultured in serum-free medium for an additional $24 \mathrm{~h}$ after LIPUS stimulation. Productions of IL-6, RANKL, and $\mathrm{PGE}_{2}$ in culture media at 14 days were determined with ELISA kits (R\&D Systems, Minneapolis, MN, USA) according to the manufacturer's instructions.

\section{Statistical analysis}

The data represent the results of three independent experiments; samples were prepared in triplicate. Each value represents a mean \pm SEM. Differences between groups were evaluated with one-way analysis of variance (ANOVA) followed by the Tukey multiple comparisons test, or with two-way ANOVA followed by the Bonferroni multiple comparisons test. Differences were considered statistically significant at $P<0.05$.

\section{Results}

\section{LIPUS inhibited LPS-induced mRNA expressions of} IL-6 and RANKL in osteoblasts

We observed the effects of LIPUS on IL-6 and RANKL LPS-induced mRNA levels. LIPUS was administered for $30 \mathrm{~min} /$ day, i.e., the duration found to have the strongest effect on osteoblasts (14). On day 14 of culture, LPS-enhanced mRNA expressions of IL-6 and RANKL in osteoblasts were 2.5-fold higher than those in the untreated control (Fig. 1a, b). However, LPS-induced 
Table 1 PCR primers used in the experiments

\begin{tabular}{lllc}
\hline Target & \multicolumn{1}{c}{ Primers } & GenBank Acc. & bp \\
\hline IL-6 & 5'-CAACGATGATGCACTTGCAGA-3' & NM_031168.1 & 142 \\
& 5'-CTCCAGGTAGCTATGGTACTCCAGA-3' & & \\
RANKL & 5'-CATGTGCCACTGAGAACCTTGAA-3' & NM_011613.3 & \multirow{2}{*}{103} \\
& 5'-CAGGTCCCAGCGCAATGTAAC-3' & & \\
COX-2 & 5'-GTAGCCAGCAAAGCCTAGAGCAAC-3' & NM_011198.4 & \multirow{2}{*}{148} \\
& 5'-CTACTGAGTACCAGGCCAGCACAA-3' & & \\
GAPDH & 5'-AAATGGTGAAGGTCGGTGTG-3' & NM_008084.2 & \multirow{2}{*}{142} \\
& 5'-TGAAGGGGTCGTTGATGG-3' & & \\
\hline
\end{tabular}

GAPDH, glyceraldehyde-3-phosphate dehydrogenase.
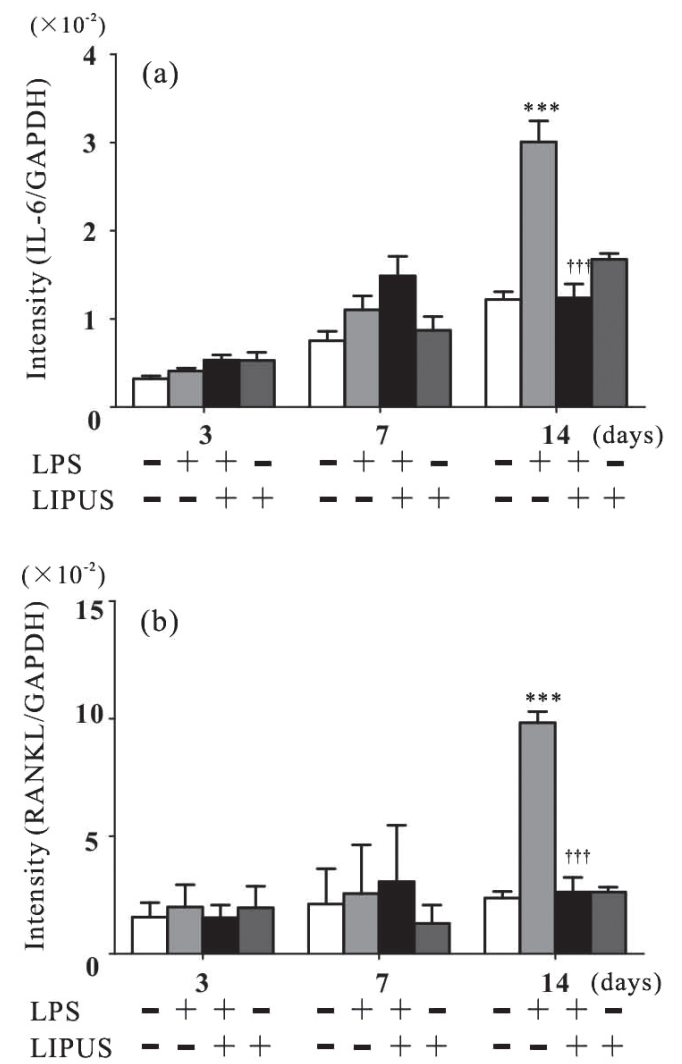

Fig. 1 Cells were stimulated with LIPUS (30 min/day) and/or LPS $(10 \mu \mathrm{g} / \mathrm{mL})$ or not stimulated (control), and real-time PCR was used to determine gene expressions of IL-6 (a) and RANKL (b) on days 3, 7, and 14 of culture. Data are expressed as the mean \pm SEM of three independent experiments performed in triplicate; $* * * P<0.001$ vs control, ${ }^{\dagger \dagger} P<0.001$ vs LPS.
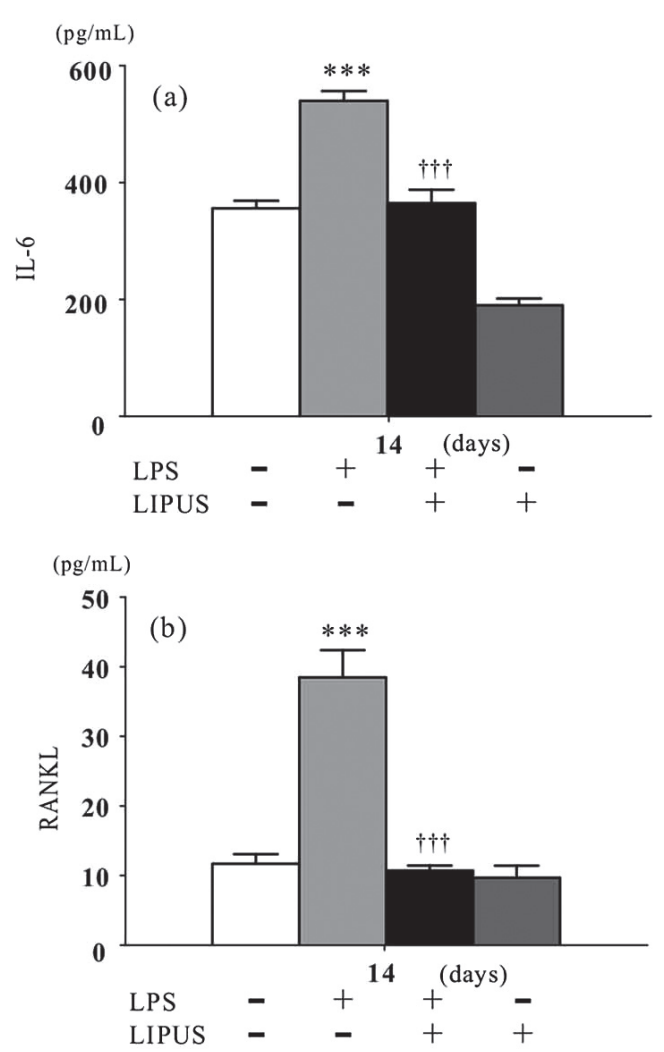

Fig. 2 Cells were stimulated with LIPUS (30 $\mathrm{min} /$ day) and/or LPS $(10 \mu \mathrm{g} / \mathrm{mL})$ or not stimulated (control), and ELISA was used to determine protein expressions of IL-6 (a) and RANKL (b) on day 14 of culture. Data are expressed as the mean \pm SEM of three independent experiments performed in triplicate; $* * * P<0.001$ vs control, ${ }^{\dagger \dagger} P<0.001$ vs LPS. upregulation of IL-6 and RANKL mRNA levels on day 14 was inhibited by LIPUS (Fig. 1).

\section{LIPUS inhibited LPS-induced protein expressions of IL-6 and RANKL in osteoblasts}

LPS increased the protein and mRNA expression levels of IL-6 and RANKL (by 1.49- and 3.0-fold, respectively) on day 14; however, LIPUS blocked the stimulatory effect of LPS on IL-6 and RANKL protein expressions (Fig. 2).

\section{Effects of LIPUS on mRNA expression of COX-2}

As compared with the untreated control, LPS increased mRNA expression of the $\mathrm{PGE}_{2}$ synthesis enzyme COX-2 by 1.42 -fold. As compared with the LPS culture, LIPUS inhibited LPS-induced COX-2 mRNA expression on day 

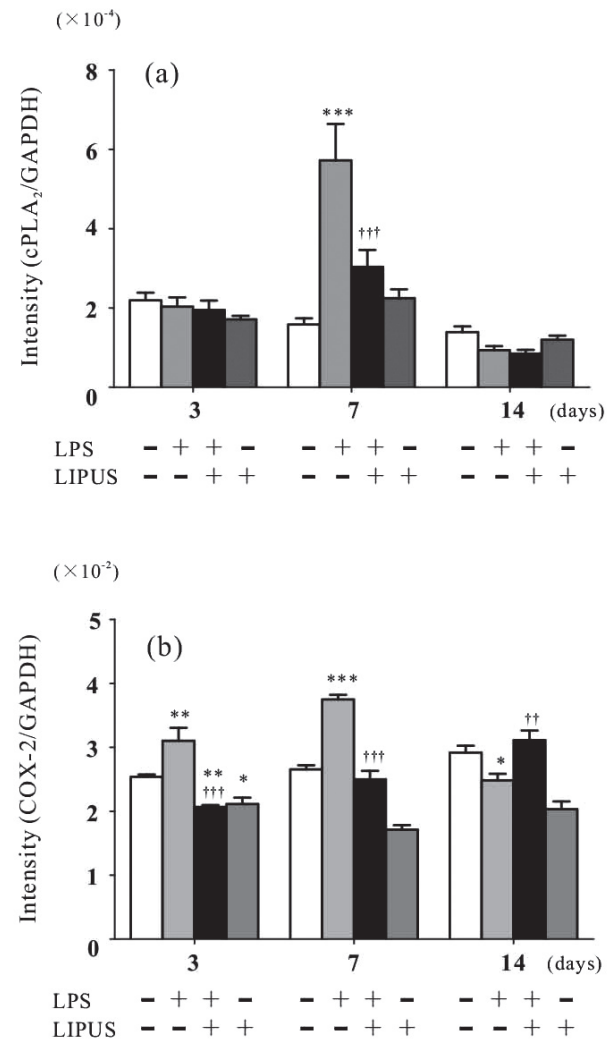

Fig. 3 Cells were stimulated with LIPUS (30 min/day) and/or LPS $(10 \mu \mathrm{g} / \mathrm{mL})$ or not stimulated (Untreated), and real-time PCR was used to determine gene expressions of COX-2 on days 3, 7, and 14 of culture. Data are expressed as the mean \pm SEM of three independent experiments performed in triplicate; $* P<0.05$, $* * P<$ $0.01, * * * P<0.001$ vs control, ${ }^{\dagger} P<0.01$, ${ }^{\dagger \dagger} P<0.001$ vs LPS.

7 (by 0.66-fold). LIPUS also reduced COX-2 mRNA expression, as compared with that of the untreated control, on days 3, 7, and 14 (by 0.83-, 0.63-, and 0.70fold, respectively). In contrast, LPS decreased COX-2 mRNA expression as compared with untreated control on day 14 (by 0.88 -fold) (Fig. 3).

\section{Effects of LIPUS on PGE2 production}

The mechanism underlying the inhibitory effect of LIPUS on LPS-induced IL-6 and RANKL expression was investigated by evaluating $\mathrm{PGE}_{2}$ expression on days 7 and 14 of culture. LPS-induced $\mathrm{PGE}_{2}$ production was 6.7 - and 8.8 -fold that of the untreated control on culture days 7 and 14, respectively. LIPUS reduced $\mathrm{PGE}_{2}$ production, as compared with LPS, by 2.1- and 1.76fold on culture days 7 and 14, respectively. In addition, LIPUS increased $\mathrm{PGE}_{2}$ production, as compared with the untreated control, by 1.6- and 3.0-fold on culture days 7 and 14, respectively (Fig. 4).

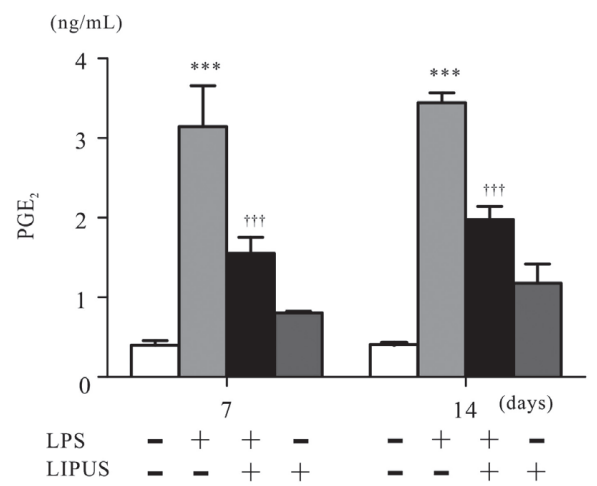

Fig. 4 Cells were stimulated with LIPUS (30 min/day) and/or LPS $(10 \mu \mathrm{g} / \mathrm{mL})$ or not stimulated (control), and ELISA was used to determine production of $\mathrm{PGE}_{2}$ on days 7 and 14 of culture. Data are expressed as the mean \pm SEM of three independent experiments performed in triplicate; ${ }^{* * *} P<0.001$ vs control, ${ }^{\dagger \dagger} P<0.001$ vs LPS.

\section{Discussion}

LPS enhances production of proinflammatory factors such as IL-1, IL-6, TNF- $\alpha$, RANKL, and prostaglandin $\mathrm{PGE}_{2}$ (19-21). Proinflammatory cytokines affect gingival epithelial cells and alveolar bone, which includes osteoblasts and osteoclasts (21). This study investigated the effects of LIPUS on LPS-induced proinflammatory cytokines in osteoblasts and showed that LIPUS blocked LPS-induced increases in IL- 6 and RANKL on day 14 of culture (Figs. 1, 2).

IL-6 is an important proinflammatory cytokine in RA and is involved in inflammatory bone disease. IL-6 knockout mice exhibit partial inhibition of osteoarthritis development (22-24), which suggests that IL-6 has a direct role in bone (25). IL-6 binds to its soluble receptor, which may promote osteoblast differentiation and activation by increasing expression of alkaline phosphatase or osteocalcin, an osteoblast differentiation marker in osteoblast precursor cells in vitro $(26,27)$. However, the effects of IL-6 on osteoblast proliferation are modest (28). In contrast, IL-6 indirectly induces osteoclastogenesis by stimulating RANKL secretion in osteoblasts (29). Thus, various cell types involved in inflammatory bone disease produce IL-6, including osteoblasts and synovial fibroblasts.

RANKL is a member of the TNF superfamily. It has roles in osteoclast differentiation and survival and is secreted from osteoblasts as a transmembrane ligand. It is also expressed on stromal cells, B-lymphoid lineage cells, and activated T-cells and exists in a soluble form (30-32). RANKL binds to receptor activator of nuclear factor kappa B (RANK), that is as part of the commitment of monocyte/macrophage precursor cells to differentiate 
into the osteoclast lineage and activation of mature osteoclasts (33). RANKL knockout mice exhibit severe osteopetrosis associated with a defect in tooth eruption, which was caused by a complete lack of osteoclasts (34-36). In contrast, RANKL transgenic mice exhibit a decrease in bone mass and an increase in the number of osteoclasts (37). Taken together, these observations indicate that IL-6 and RANKL are important factors in bone resorption leading to inflammation in osteoarthritis and periodontitis.

Mechanical stimulation from pressure, fluid shear, tension strain, and LIPUS result in varied biological responses (38-40). LIPUS induces osteogenesis in osteoblasts $(14,16)$. Previous reports indicate that osteoblasts respond to mechanotransduction. Osteoblasts possess mechanoreceptors in the form of ion channels, integrins, connexins, $\mathrm{G}$ protein-coupled receptors, and $\mathrm{P} 2$ receptors $(38,41,42)$. An evaluation of the clinical effects of LIPUS on bone fracture healing (43) found that LIPUS induced osteogenesis while inhibiting adipogenesis in mouse bone marrow cells (44). In the present study, LIPUS suppressed expression of IL-6 and RANKL (Figs. 1, 2). These results showed that LIPUS is a response to LPSinduced osteoblasts that are present during inflammation.

$\mathrm{PGE}_{2}$ is a member of the eicosanoid family of lipid mediators and is produced by nearly all cells. It is synthesized from arachidonic acid, via the actions of COX enzymes, in response to cell-specific trauma, stimuli, and signaling molecules. $\mathrm{PGE}_{2}$ is not stored in cells (45-47). $\mathrm{PGE}_{2}$ is also an important mediator of inflammatory bone diseases such as osteoarthritis and periodontitis (48). A previous study reported that $\mathrm{PGE}_{2}$ induced RANKL and IL-6 production. In contrast, the COX-2 inhibitor NS398 reduced production of RANKL and IL-6 in MC3T3-E1 cells (49). These previous findings indicate that $\mathrm{PGE}_{2}$ stimulates IL- 6 and RANKL production via COX-2 in osteoblasts. In the present study, LPS induced COX-2, IL-6, and RANKL, as well as mRNA expression and $\mathrm{PGE}_{2}$ production. However, the mRNA level of COX-2 was decreased by LPS on day 14 of culture, perhaps because of a biological response, as the maximum effects of LPS on the proinflammatory cytokines IL- 6 and RANKL were seen on day 14. MC3T3-E1 cells exhibited progressive inflammation and subsequent anti-inflammatory responses, to recover from inflammation. These results are consistent with those of previous studies. Furthermore, our present study showed that LIPUS suppressed the LPS-induced stimulatory effects on IL-6, RANKL, COX-2, and $\mathrm{PGE}_{2}$ in osteoblasts (Figs. 1-4). These results suggest that LIPUS exerts anti-inflammatory effects by reducing IL-6 and RANKL production via inhibition of $\mathrm{PGE}_{2}$ and COX-2 expression in osteoblasts. However, LIPUS also increased $\mathrm{PGE}_{2}$ production while inhibiting IL-6 and RANKL expression (Fig. 4). $\mathrm{PGE}_{2}$ affects both bone resorption-which involves inflammation - and bone formation in osteoblasts $(48,50,51)$. Mechanical stimuli also induce osteogenesis via $\mathrm{PGE}_{2}$ production in osteoblasts (50). Thus, in the present study LIPUS stimulated $\mathrm{PGE}_{2}$, which might be involved in osteogenesis. Our findings indicate that the molecular mechanism underlying the anti-inflammatory effects of LIPUS is a possible target for future treatments for RA, osteoarthritis, and periodontitis. Furthermore, the pathway mediating the inhibitory effects of LIPUS on IL-6, RANKL, and $\mathrm{PGE}_{2}$ production should be further investigated.

\section{Acknowledgments}

The LIPUS device (OSTEOTRON $\mathrm{D}^{2}$ ) was supplied by Ito Co. Ltd. This study was supported by the Sato Fund (2016) and Uemura Fund (2016), Nihon University School of Dentistry.

\section{Conflicts of interest}

None declared.

\section{References}

1. Eke PI, Dye BA, Wei L, Thornton-Evans GO, Genco RJ (2012) Prevalence of periodontitis in adults in the United States: 2009 and 2010. J Dent Res 91, 914-920.

2. Rhee SH (2014) Lipopolysaccharide: basic biochemistry, intracellular signaling, and physiological impacts in the gut. Intest Res 12, 90-95.

3. Lopalco G, Cantarini L, Vitale A, Iannone F, Anelli MG, Andreozzi L et al. (2015) Interleukin-1 as a common denominator from autoinflammatory to autoimmune disorders: premises, perils, and perspectives. Mediators Inflamm 2015, 194864.

4. Zou W, Bar-Shavit Z (2002) Dual modulation of osteoclast differentiation by lipopolysaccharide. J Bone Miner Res 17, 1211-1218.

5. Ishimi $\mathrm{Y}$, Miyaura $\mathrm{C}$, Jin $\mathrm{CH}$, Akatsu $\mathrm{T}$, Abe E, Nakamura $\mathrm{Y}$ et al. (1990) IL-6 is produced by osteoblasts and induces bone resorption. J Immunol 145, 3297-3303.

6. Kato H, Taguchi Y, Tominaga K, Umeda M, Tanaka A (2014) Porphyromonas gingivalis LPS inhibits osteoblastic differentiation and promotes pro-inflammatory cytokine production in human periodontal ligament stem cells. Arch Oral Biol 59, 167-175.

7. Kassem A, Henning P, Lundberg P, Souza PP, Lindholm C, Lerner UH (2015) Porphyromonas gingivalis stimulates bone resorption by enhancing RANKL (receptor activator of NF- $\kappa B$ ligand) through activation of Toll-like receptor 2 in osteoblasts. J Biol Chem 290, 20147-20158.

8. Warden SJ, Bennell KL, McMeeken JM, Wark JD (2000) 
Acceleration of fresh fracture repair using the sonic accelerated fracture healing system (SAFHS): a review. Calcif Tissue Int 66, 157-163.

9. Nolte PA, van der Krans A, Patka P, Janssen IM, Ryaby JP, Albers GH (2001) Low-intensity pulsed ultrasound in the treatment of nonunions. J Trauma 51, 693-702.

10. Gebauer D, Mayr E, Orthner E, Ryaby JP (2005) Lowintensity pulsed ultrasound: effects on nonunions. Ultrasound Med Biol 31, 1391-1402.

11. Roussignol X, Currey C, Duparc F, Dujardin F (2012) Indications and results for the Exogen ${ }^{\mathrm{TM}}$ ultrasound system in the management of non-union: a 59-case pilot study. Orthop Traumatol Surg Res 98, 206-213.

12. Harrison A, Lin S, Pounder N, Mikuni-Takagaki Y (2016) Mode \& mechanism of low intensity pulsed ultrasound (LIPUS) in fracture repair. Ultrasonics 70, 45-52.

13. Salem KH, SchmelzA(2014) Low-intensity pulsed ultrasound shortens the treatment time in tibial distraction osteogenesis. Int Orthop 38, 1477-1482.

14. Manaka S, Tanabe N, Kariya T, Naito M, Takayama T, Nagao $\mathrm{M}$ et al. (2015) Low-intensity pulsed ultrasound-induced ATP increases bone formation via the $\mathrm{P} 2 \mathrm{X} 7$ receptor in osteoblastlike MC3T3-E1 cells. FEBS Lett 589, 310-318.

15. Elsner HI, Lindblad EB (1989) Ultrasonic degradation of DNA. DNA 8, 697-701.

16. Takayama T, Suzuki N, Ikeda K, Shimada T, Suzuki A, Maeno $\mathrm{M}$ et al. (2007) Low-intensity pulsed ultrasound stimulates osteogenic differentiation in ROS 17/2.8 cells. Life Sci 80, 965-971.

17. Nakao J, Fujii Y, Kusuyama J, Bandow K, Kakimoto K, Ohnishi T et al. (2014) Low-intensity pulsed ultrasound (LIPUS) inhibits LPS-induced inflammatory responses of osteoblasts through TLR4-MyD88 dissociation. Bone 58, 17-25.

18. Takahashi Y, Tanaka H, Nakai K, Kitami S, Murakami F, Morita $\mathrm{T}$ et al. (2016) RANKL induces IL-18 binding protein expression in RAW264.7 cells. J Hard Tissue Biol 25, 173-180.

19. Keeting PE, Rifas L, Harris SA, Colvard DS, Spelsberg TC, Peck WA et al. (1991) Evidence for interleukin-1 $\beta$ production by cultured normal human osteoblast-like cells. J Bone Miner Res 6, 827-833.

20. Page RC (1991) The role of inflammatory mediators in the pathogenesis of periodontal disease. J Periodontal Res 26, 230-242.

21. Shoji M, Tanabe N, Mitsui N, Tanaka H, Suzuki N, Takeichi O et al. (2006) Lipopolysaccharide stimulates the production of prostaglandin $\mathrm{E}_{2}$ and the receptor Ep4 in osteoblasts. Life Sci 78, 2012-2018.

22. Ohshima S, Saeki Y, Mima T, Sasai M, Nishioka K, Nomura $\mathrm{S}$ et al. (1998) Interleukin 6 plays a key role in the development of antigen-induced arthritis. Proc Natl Acad Sci U S A 95, 8222-8226.

23. Sasai M, Saeki Y, Ohshima S, Nishioka K, Mima T, Tanaka T et al. (1999) Delayed onset and reduced severity of collagen- induced arthritis in interleukin-6-deficient mice. Arthritis Rheum 42, 1635-1643.

24. Boe A, Baiocchi M, Carbonatto M, Papoian R, SerlupiCrescenzi O (1999) Interleukin 6 knock-out mice are resistant to antigen-induced experimental arthritis. Cytokine 11, 10571064.

25. Le Goff B, Blanchard F, Berthelot JM, Heymann D, Maugars Y (2010) Role for interleukin-6 in structural joint damage and systemic bone loss in rheumatoid arthritis. Joint Bone Spine 77, 201-205.

26. Bellido T, Stahl N, Farruggella TJ, Borba V, Yancopoulos GD, Manolagas SC (1996) Detection of receptors for interleukin-6, interleukin-11, leukemia inhibitory factor, oncostatin $\mathrm{M}$, and ciliary neurotrophic factor in bone marrow stromal/osteoblastic cells. J Clin Invest 97, 431-437.

27. Taguchi Y, Yamamoto M, Yamate T, Lin SC, Mocharla H, DeTogni P et al. (1998) Interleukin-6-type cytokines stimulate mesenchymal progenitor differentiation toward the osteoblastic lineage. Proc Assoc Am Physicians 110, 559-574.

28. Heymann D, Rousselle AV (2000) gp130 cytokine family and bone cells. Cytokine 12, 1455-1468.

29. Palmqvist P, Persson E, Conaway HH, Lerner UH (2002) IL-6, leukemia inhibitory factor, and oncostatin $\mathrm{M}$ stimulate bone resorption and regulate the expression of receptor activator of NF- $\mathrm{BB}$ ligand, osteoprotegerin, and receptor activator of NF- $\kappa \mathrm{B}$ in mouse calvariae. J Immunol 169, 3353-3362.

30. Lacey DL, Timms E, Tan HL, Kelley MJ, Dunstan CR, Burgess T et al. (1998) Osteoprotegerin ligand is a cytokine that regulates osteoclast differentiation and activation. Cell 93, 165-176.

31. Yasuda H, Shima N, Nakagawa N, Yamaguchi K, Kinosaki M, Mochizuki S et al. (1998) Osteoclast differentiation factor is a ligand for osteoprotegerin/osteoclastogenesis-inhibitory factor and is identical to TRANCE/RANKL. Proc Natl Acad Sci U S A 95, 3597-3602.

32. Manabe N, Kawaguchi H, Chikuda H, Miyaura C, Inada M, Nagai R et al. (2001) Connection between B lymphocyte and osteoclast differentiation pathways. J Immunol 167, 26252631.

33. Takayanagi H (2007) Osteoimmunology: shared mechanisms and crosstalk between the immune and bone systems. Nat Rev Immunol 7, 292-304.

34. Kong YY, Yoshida H, Sarosi I, Tan HL, Timms E, Capparelli $\mathrm{C}$ et al. (1999) OPGL is a key regulator of osteoclastogenesis, lymphocyte development and lymph-node organogenesis. Nature 397, 315-323.

35. Dougall WC, Glaccum M, Charrier K, Rohrbach K, Brasel K, De Smedt T et al. (1999) RANK is essential for osteoclast and lymph node development. Genes Dev 13, 2412-2424.

36. Li J, Sarosi I, Yan XQ, Morony S, Capparelli C, Tan HL et al. (2000) RANK is the intrinsic hematopoietic cell surface receptor that controls osteoclastogenesis and regulation of bone mass and calcium metabolism. Proc Natl Acad Sci U S A $97,1566-1571$. 
37. Mizuno A, Kanno T, Hoshi M, Shibata O, Yano K, Fujise N et al. (2002) Transgenic mice overexpressing soluble osteoclast differentiation factor (sODF) exhibit severe osteoporosis. J Bone Miner Metab 20, 337-344.

38. Genetos DC, Geist DJ, Liu D, Donahue HJ, Duncan RL (2005) Fluid shear-induced ATP secretion mediates prostaglandin release in MC3T3-E1 osteoblasts. J Bone Miner Res 20, 41-49.

39. Robling AG, Castillo AB, Turner CH (2006) Biomechanical and molecular regulation of bone remodeling. Annu Rev Biomed Eng 8, 455-498.

40. Kariya T, Tanabe N, Shionome C, Manaka S, Kawato T, Zhao $\mathrm{N}$ et al. (2015) Tension force-induced ATP promotes osteogenesis through $\mathrm{P} 2 \mathrm{X} 7$ receptor in osteoblasts. J Cell Biochem $116,12-21$.

41. Ke HZ, Qi H, Weidema AF, Zhang Q, Panupinthu N, Crawford DT et al. (2003) Deletion of the P2X7 nucleotide receptor reveals its regulatory roles in bone formation and resorption. Mol Endocrinol 17, 1356-1367.

42. Rubin J, Rubin C, Jacobs CR (2006) Molecular pathways mediating mechanical signaling in bone. Gene 367, 1-16.

43. Romano CL, Romano D, Logoluso N (2009) Low-intensity pulsed ultrasound for the treatment of bone delayed union or nonunion: a review. Ultrasound Med Biol 35, 529-536.

44. Kusuyama J, Bandow K, Shamoto M, Kakimoto K, Ohnishi T, Matsuguchi T (2014) Low-intensity pulsed ultrasound (LIPUS) influences the multi-lineage differentiation of mesenchymal stem and progenitor cell lines through ROCK-
Cot/Tpl2-MEK-ERK signaling pathway. J Biol Chem 289, 10330-10344.

45. Smith WL (1989) The eicosanoids and their biochemical mechanisms of action. Bioochem J 259, 315-324.

46. Berenbaum F (2000) Proinflammatory cytokines, prostaglandins, and the chondrocyte: mechanisms of intracellular activation. Joint Bone Spine 67, 561-564.

47. Funk CD (2001) Prostaglandins and leukotrienes: advances in eicosanoid biology. Science 294, 1871-1875.

48. Park JY, Pillinger MH, Abramson SB (2006) Prostaglandin $\mathrm{E}_{2}$ synthesis and secretion: the role of $\mathrm{PGE}_{2}$ synthases. Clin Immunol 119, 229-240.

49. Liu XH, Kirschenbaum A, Yao S, Levine AC (2005) Crosstalk between the interleukin- 6 and prostaglandin $\mathrm{E}_{2}$ signaling systems results in enhancement of osteoclastogenesis through effects on the osteoprotegerin/receptor activator of nuclear factor- $\mathrm{\kappa B}$ (RANK) ligand/RANK system. Endocrinology 146, 1991-1998.

50. Mitsui N, Suzuki N, Maeno M, Yanagisawa M, Koyama Y, Otsuka $\mathrm{K}$ et al. (2006) Optimal compressive force induces bone formation via increasing bone morphogenetic proteins production and decreasing their antagonists production by Saos-2 cells. Life Sci 78, 2697-2706.

51. Panupinthu N, Rogers JT, Zhao L, Solano-Flores LP, Possmayer F, Sims SM et al. (2008) P2X7 receptors on osteoblasts couple to production of lysophosphatidic acid: a signaling axis promoting osteogenesis. J Cell Biol 181, 859-871. 